\title{
Self-assembly of cholesterol end-capped polymer micelles for controlled drug delivery
}

Ming Gao ${ }^{1,2^{*}} \mathbb{D}$, Yifeng Yang ${ }^{1,2}$, Andreas Bergfel ${ }^{3}$, Lanli Huang ${ }^{4}$, Li Zheng ${ }^{1,2^{*}}$ and Tim Melander Bowden ${ }^{3^{*}}$

\begin{abstract}
Background: During the past few decades, drug delivery system (DDS) has attracted many interests because it could enhance the therapeutic effects of drugs and reduce their side effects. The advent of nanotechnology has promoted the development of nanosized DDSs, which could promote drug cellular uptake as well as prolong the half-life in blood circulation. Novel polymer micelles formed by self-assembly of amphiphilic polymers in aqueous solution have emerged as meaningful nanosystems for controlled drug release due to the reversible destabilization of hydrophobic domains under different conditions.

Results: The amphiphilic polymers presented here were composed of cholesterol groups end capped and poly (poly (ethylene glycol) methyl ether methacrylate) (poly (OEGMA)) as tailed segments by the synthesis of cholesterol-based initiator, followed by atom transfer radical polymerization (ATRP) with OEGMA monomer. FT-IR and NMR confirmed the successfully synthesis of products including initiator and polymers as well as the Mw of the polymers were from 33,233 to $89,088 \mathrm{~g} / \mathrm{mol}$ and their corresponding PDI were from 1.25 to 1.55 by GPC. The average diameter of assembled polymer micelles was in hundreds nanometers demonstrated by DLS, AFM and SEM. The behavior of the amphiphilic polymers as micelles was investigated using pyrene probing to explore their critical micelle concentration (CMC) ranging from $2.53 \times 10^{-4}$ to $4.33 \times 10^{-4} \mathrm{mg} / \mathrm{ml}$, decided by the balance between cholesterol and poly (OEGMA). Besides, the CMC of amphiphilic polymers, the quercetin (QC) feeding ratio and polarity of solvents determined the QC loading ratio maximized reaching 29.2\% certified by UV spectrum, together with the corresponding size and stability changes by DLS and Zeta potential, and thermodynamic changes by TGA and DSC. More significantly, cholesterol end-capped polymer micelles were used as nanosized systems for controlled drug release, not only alleviated the cytotoxicity of QC from 8.6 to $49.9 \%$ live cells and also achieved the QC release in control under different conditions, such as the presence of cyclodextrin (CD) and change of pH in aqueous solution.
\end{abstract}

Conclusions: The results observed in this study offered a strong foundation for the design of favorable polymer micelles as nanosized systems for controlled drug release, and the molecular weight adjustable amphiphilic polymer micelles held potential for use as controlled drug release system in practical application.

Keywords: Atom transfer radical polymerization, Supermolecular self-assembly, Amphiphilic polymer micelles, Critical micelle concentration, Controlled drug delivery system

*Correspondence: gaoming1983125@hotmail.com; zhengli224@163.com; tim.bowden@kemi.uu.se

${ }^{1}$ Guangxi Engineering Center in Biomedical Materials for Tissue and Organ Regeneration, The First Affiliated Hospital of Guangxi Medical University, Nanning 530021, China

${ }^{3}$ Department of Chemistry-Ångström Laboratory, Uppsala University, Box 538, 75121 Uppsala, Sweden

Full list of author information is available at the end of the article

\section{Background}

Many drugs have unacceptable side effects due to unwanted interactions with non-targeted parts of the body $[1,2]$. These side effects hamper the ability to design optimal medical regimes for treatment of diseases and call for the development of drug delivery system (DDS) strategies. DDS, referring to enhance therapeutic effects 
of drug molecules and reduce their related side effects, attracts many interests during the past few decades [3, 4]. An ideal DDS would control the localization, presentation and release of active drugs in the target tissue or cellular compartment within a predefined concentration during a specified period of time.

The advent of nanotechnology has promoted the design of nanoparticles, [5, 6] nanocapsules, [7, 8] polymer micelles $[9,10]$ and liposome $[11,12]$ as nanosized DDSs. Specifically, polymer micelles derived from the selfassembly of amphiphilic polymers has sparked an interest as DDSs since they can be prepared in nanometer size, in order to promote cellular uptake and with the potential benefit of an increased half-life in blood circulation [13, 14]. However, the formation of polymer micelles is mostly built by the structural design of the polymer where hydrophobic and hydrophilic segments are combined in so called amphiphilic polymers [15]. Their hydrophobicity can be reached by the introduction of hydrophobic groups such as fluorination, $[16,17]$ cholesterol, $[18,19]$ ferrocene, $[20,21]$ pyrene, $[22,23]$ polyesters $[24,25]$ and these groups will form domains which can encapsulate lipophilic therapeutic drugs. Meanwhile, their hydrophilic segments could be selected from natural polymers such as polysaccharides, [26] polypeptides, [27, 28] or synthetic polymers including poly (ethylene glycol) (PEG) and PEG-ylated polymers [15, 29]. Herein, an important parameter for polymer micelle formation is the critical micelle concentration (CMC), which mainly depends on the balance between hydrophilic and hydrophobic segments. Besides, the types of hydrophobic group, molecular weight and distribution of hydrophilic parts in the amphiphilic polymer also influence the CMC as well as the stability of polymeric micelle and the drug loading ratio [30]. For instance, cholesterol is a hydrophobic molecule and natural component of the cell membrane, widely used in liposomes with good biocompatibility [18, $19,31]$. Finally, strategies for controlled release from DDS aim for creating reversible conditions by destabilizing the micelles at intracellular conditions including lowering of $\mathrm{pH},[32,33]$ temperature, [7] glutathione, [34, 35] specific enzymes, [5, 36] and external factors: light, [37] magnetic field, [38, 39] electric field [20, 21] and other molecules [40, 41]. In this respect, amphiphilic polymer micelles could be used to optimize DDSs by chemically modulating the core-shell structure of micelles in order to match selected drugs and the physiological conditions $[9,10]$.

Motivated by these findings, we present the preparation of amphiphilic cholesterol end-capped poly (poly (ethylene glycol) methyl ether methacrylate)s, abbreviated as $\mathrm{CO}$ polymers, use them to form polymer micelles and evaluate their effects as controlled DDS by the presence of $\beta$-cyclodextrin or change of $\mathrm{pH}$. The polymers are comprised of a hydrophilic outer shell of poly (poly (ethylene glycol) methyl ether methacrylate), abbreviated as poly (OEGMA), and a hydrophobic inner core of cholesterol and can form nanoscale micelles in aqueous medium by self-aggregations. Atom transfer radical polymerization (ATRP) is used to synthesize the amphiphilic polymers with controlled polymer molecular weight and narrow molecular weight distribution, [42] which could significantly affect the critical micelle concentration $(\mathrm{CMC})$ and drug loading ratio. Here quercetin $(\mathrm{QC})$ is selected as a model drug due to its anti-tumor activity, reported inhibition of allergic and inflammatory responses of the immune system, and preventing growth of bacteria and fungi plus being a vasoprotective and an antithrombotic agent [24]. The polymer micelles are expected to encapsulate the hydrophobic drug and perform a controlled release affected by either $\mathrm{pH}$ or the induced host-guest interaction between cholesterol and $\beta$-cyclodextrin. Figure 1 illustrates the schematic procedures of self-assembly of CO-QC polymer micelles and their host-guest interaction with $\beta$-cyclodextrin to reach controlled drug release.

\section{Experimental section}

Materials and equipment

Cholesterol $(\geq 99 \%), \alpha$-bromoisobutyryl bromide (98\%), triethylamine ( $\geq 99 \%), 2$,2-bipyridyl (bpy, $\geq 99 \%$ ), magnesium sulfate $(\geq 99.5 \%)$, silica gel (high-purity grade, pore size $60 \AA$ А $200-425$ mesh particle size),

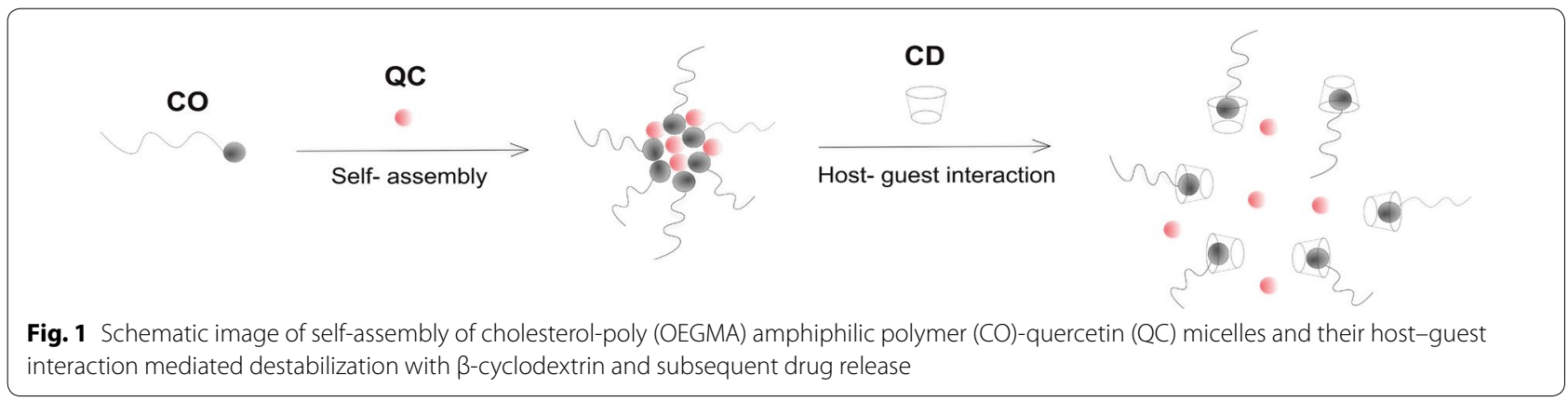


copper (II) chloride $\left(\mathrm{CuCl}_{2}, \geq 99 \%\right)$, copper (I) chloride $(\mathrm{CuCl} \geq 99.99 \%)$, anisole (99.7\%), oligo (ethylene glycol) methyl ether methacrylate (OEGMA, average $\left.\mathrm{M}_{\mathrm{n}}=500 \mathrm{~g} / \mathrm{mol}\right)$, aluminum oxide $\left(\mathrm{Al}_{2} \mathrm{O}_{3}\right.$ basis, $\left.\geq 98 \%\right)$, pyrene (99\%), quercetin (QC, $\geq 95 \%), \quad \beta$-cyclodextrin $(\geq 97 \%)$ were obtained from Sigma-Aldrich. Solvents (diethyl ether, methylene chloride (DCM), methanol, tetrahydrofuran (THF) and acetone) were purchased from VWR and in analytical grade. Chemicals were used without further treatment with the exceptions for OEGMA that was purified by passing through basic $\mathrm{Al}_{2} \mathrm{O}_{3}$ to remove the inhibitor and the recrystallization of $\mathrm{QC}$ from acetone.

The synthesized cholesterol initiator and polymers were characterized by Fourier transform infrared spectra (FTIR, PerkinElmer spectrum One FT-IR spectrometer), ${ }^{1} \mathrm{H}$ NMR spectra $(400 \mathrm{MHz}$, Jeol JNM-ECP Series FT $\mathrm{NMR})$ using deuterated chloroform $\left(\mathrm{CDCl}_{3}\right)$ as solvent and gel permeation chromatography (GPC, Agilent Technologies, 1260 infinity). Atomic force microscopy (AFM) and scanning electron microscopy (SEM) was recorded on Nanosurf Mobile S, TS150 and Leo 1550 SEM instrument Zeiss, Germany respectively. Particle size and distribution was investigated using a zeta sizer nano instrument from Malvern Instruments, UK. Thermal properties were studied on lyophilized samples by thermogravimetric analysis on TGA Q500, and differential scanning calorimetry on DSC Q1000 (TA instruments).

\section{Synthesis of CO polymers}

Cholesterol end-capped polymers were synthesized using a two-step procedure. In step one a cholesterol initiator (Chol-Br) was synthesized. Briefly, cholesterol $(1.0 \mathrm{~g}, 2.6 \mathrm{mmol})$ was dissolved in $150 \mathrm{ml}$ of diethyl ether followed by the addition of triethylamine $(0.47 \mathrm{ml}$, $3.4 \mathrm{mmol}$ ). The mixture was placed on an ice bath and $\alpha$-bromoisobutyryl bromide $(0.72 \mathrm{~g}, 1.34 \mathrm{ml}, 3.1 \mathrm{mmol}$ ) was added dropwise. After two hours a white ammonium salt precipitate was filtered off by vacuum filtration. Additional solvent $\left(\mathrm{CH}_{2} \mathrm{Cl}_{2}\right)$ was added and the organic phase was washed for three times with water, dried with $\mathrm{MgSO}_{4}$ and filtered. The organic phase was further passed through a plug of silica, evaporated and additionally dried in vacuum to afford the Chol- $\mathrm{Br}$ as a white solid. In the second step, the amphiphilic cholesterol end-capped poly (OEGMA) (CO) was prepared by ATRP as follows: cholesterol- $\mathrm{Br}(0.021 \mathrm{~g})$ was dissolved in anisole $(5 \mathrm{ml})$ after combining with $\mathrm{CuCl}_{2}(0.27 \mathrm{mg})$ and bpy $(0.013 \mathrm{~g})$. Subsequently a certain amount of OEGMA monomer $(8 \mathrm{~g})$ was added to the mixture. The final mixture was vacuumed to remove oxygen by repeated freezing, pump and thawing steps. The reaction mixture was heated at $60{ }^{\circ} \mathrm{C}$ for $24 \mathrm{~h}$ with monitoring the reaction progress by NMR. After reaction, the mixture firstly was quenched with acetone, before filtered through a silica gel column followed by the basic $\mathrm{Al}_{2} \mathrm{O}_{3}$ column to remove excess copper elements as previously done [43, 44]. The final product was precipitated in diethyl ether before vacuum drying. A series of polymers varying in degree of polymerization were produced using the same protocol and were defined as CO50, CO100, and CO200 by the feed molar ratio between cholesterol-Br and OEGMA.

\section{Preparation of quercetin (QC) loaded polymer micelles}

Polymer micelles with or without QC were prepared as follows. The polymer and a predetermined amount of QC were separately dissolved in different solvent (acetone, DCM, methanol or THF). Then the obtained mixture was added dropwise to PBS buffer under stirring to form the polymer complexes overnight. After evaporation of solvents, the final solutions were dialyzed (Spectra/Por ${ }^{\circledR} 6$ Dialysis Membrane, MWCO: 3.5 KD) against deionized water for $24 \mathrm{~h}$ to remove the free $\mathrm{QC}$ to obtain the QCloaded polymer micelle solution.

\section{Measurement of critical micelle concentration (CMC) of polymer micelles}

The CMC measurements of polymer micelles were implemented by fluorescent microscopy (Luminescence Spectrometer, LS45, PerkinElmer Instrument). Pyrene was used as a fluorescence probe to analyze the polymer micelles in PBS buffer $(\mathrm{pH}=7.4)$. Samples for fluorescent microscopy were prepared as previously described [45, 46]. Cholesterol end-capped polymers and pyrene were dissolved in the methanol before the drop-wise addition of PBS buffer. The mixture was stirring overnight to reach the total evaporation of solvents. The concentration of polymers ranged from $1 \times 10^{-6}$ to $0.1 \mathrm{mg} / \mathrm{ml}$ while the pyrene concentration was chosen to $4.5 \times 10^{-5} \mathrm{mg} / \mathrm{ml}$ in the final solution. The slit widths for both excitation and emission sides were maintained at $2.5 \mathrm{~nm}$ and excitation and emission wavelength of $339 \mathrm{~nm}$ and $374 \mathrm{~nm}$ were respectively applied.

\section{Determination of QC loading ratio}

The polymer-QC micelle solutions were mixing with THF with the volume ratio of $1: 1$. The final solutions were investigated by UV-Vis spectroscopy (Lambda $35 \mathrm{UV} / \mathrm{Vis}$ spectrometer, PerkinElmer Instrument) at the wavelength of $380 \mathrm{~nm}$. The QC standard curve was obtained by measuring the QC solutions (THF: PBS buffer with volume ratio of $1: 1$ ) of various concentrations. Finally, the QC loading ratio was calculated by the obtained absorbance based on the QC standard curve. 


\section{Cell cytotoxicity of polymer and polymer micelles}

Mouse myoblast cells (C2C12) were cultured in Dulbecco's modified eagle medium (DMEM, Life technologies) supplemented with $10 \%$ fetal bovine serum (FBS, Life technologies) and $0.1 \%$ penicillin-streptomycin to near $80 \%$ confluence. Cells were maintained at $37{ }^{\circ} \mathrm{C}$ with $5 \%$ $\mathrm{CO}_{2}$ at $90 \%$ humidity for $24 \mathrm{~h}$ and then seeded in 96-well plates with the density of 8000 cells per ml. Cells were replaced with fresh medium and then respectively added the corresponding sample solutions (polymer micelles, polymer-QC micelles or QC) to reach total $100 \mu \mathrm{l}$ medium in each of wells. After incubated for another $24 \mathrm{~h}$, the cells were washed with PBS buffer and $100 \mu \mathrm{l}$ $1 \%$ alamar blue solution (Life technologies) was added to each well. The plate was incubated at $37^{\circ} \mathrm{C}, 5 \% \mathrm{CO}_{2}$ for $2 \mathrm{~h}$. The absorbance was measured at $570 \mathrm{~nm}$ in a microplate reader (Tecan infinite M200). The final results were compared with control wells to determine the relative cell viability.

\section{In vitro investigation of $Q C$ release}

Polymer-QC micelle samples $(0.5 \mathrm{ml})$ were saved in dialysis tube (Slide-A-Lyzer MINI Dialysis Devices, $3.5 \mathrm{~K}$ MWCO, Fisher) and suspended in a cut-off of $15 \mathrm{ml}$ centrifuge tube ( $4.5 \mathrm{ml}$ release medium). The release study was performed at room temperature in an incubator shaker. At selected time intervals, solutions $(0.5 \mathrm{ml})$ outside of dialysis tube were removed and combined with the same volume of methanol as released samples, and then replaced with fresh release medium. The concentrations of QC in release samples were analyzed by high performance liquid chromatography (HPLC, WATERS e2695) with a 2489 UV/Vis detector. QC samples with different concentration were applied to prepare the standard curve. HPLC was running at gradient mode by the mobile phase of methanol-phosphoric acid buffer (0.7\% in milli-Q water) with volume ratio from 0: 100 to 80: 20 . The flow rate was $1 \mathrm{ml} / \mathrm{min}$ and elution time was 9 min for each sample with $\mathrm{C} 18$ column (X Bridge
$3.5 \mathrm{~m}, 4.6 \times 50 \mathrm{~mm}$ Column, WATERS). The absorbance was chosen at $360 \mathrm{~nm}$ wavelength with the elution time of $0.75 \mathrm{~min}$.

\section{Results and discussion}

Synthesis of cholesterol-Br and amphiphilic polymers

The amphiphilic cholesterol end-capped polymers were synthesized by atomic transfer radical polymerization (ATRP). Its synthetic procedures were schematically illustrated in Fig. 2. The cholesterol-Br was prepared by the reaction between cholesterol and $\alpha$-bromoisobutyryl bromide to form the initiator for ATRP. Subsequently, the amphiphilic polymer (CO) was synthesized by ATRP using the bpy as the ligand and anisole as the solvent at $70{ }^{\circ} \mathrm{C}$. From GPC data, the Mw and PDI for synthesized polymers were respectively: CO50 $(\mathrm{Mw}=33,233 \mathrm{~g} / \mathrm{mol}$, $\mathrm{PDI}=1.25), \quad \mathrm{CO} 100 \quad(\mathrm{Mw}=52,168 \mathrm{~g} / \mathrm{mol}, \mathrm{PDI}=1.32)$, and CO200 $(\mathrm{Mw}=89,088 \mathrm{~g} / \mathrm{mol}, \mathrm{PDI}=1.55)$.

\section{FT-IR and ${ }^{1} \mathrm{H}$ NMR of cholesterol-Br and amphiphilic polymers}

The cholesterol initiator and polymers were characterized by FT-IR and NMR. Figure 3 illustrated the FT-IR results of the chemical samples. The peak at $3417 \mathrm{~cm}^{-1}$ was $\mathrm{OH}$ groups for cholesterol while it disappeared in cholesterol$\mathrm{Br}$. The appearance of peak at $1729 \mathrm{~cm}^{-1}(\mathrm{C}=\mathrm{O})$ also gave the proof of successful formation of cholesterol-Br. Besides, the peaks at $1631 \mathrm{~cm}^{-1}$ and $2877 \mathrm{~cm}^{-1}$ respectively corresponded to $\mathrm{C}=\mathrm{C}$ and $-\mathrm{CH}$ stretch vibration of OEGMA monomer. It finally confirmed the successful preparation of amphiphilic polymers (CO50, CO100 and CO200) due to the inclusion of the peaks at 1729 , 1266 and $1155 \mathrm{~cm}^{-1}$ for cholesterol- $\mathrm{Br}$ and $2877 \mathrm{~cm}^{-1}$ for OEGMA.

The corresponding ${ }^{1} \mathrm{H}$ NMR results were shown in Fig. 4 with the solvent peak of $\mathrm{CDCl}_{3}$ at $7.25 \mathrm{ppm}$. The observed proton $(\mathrm{C}=\mathrm{C})$ was at $5.33 \mathrm{ppm}$ for pristine cholesterol and a slight shift at $5.39 \mathrm{ppm}$ for cholesterol-Br.

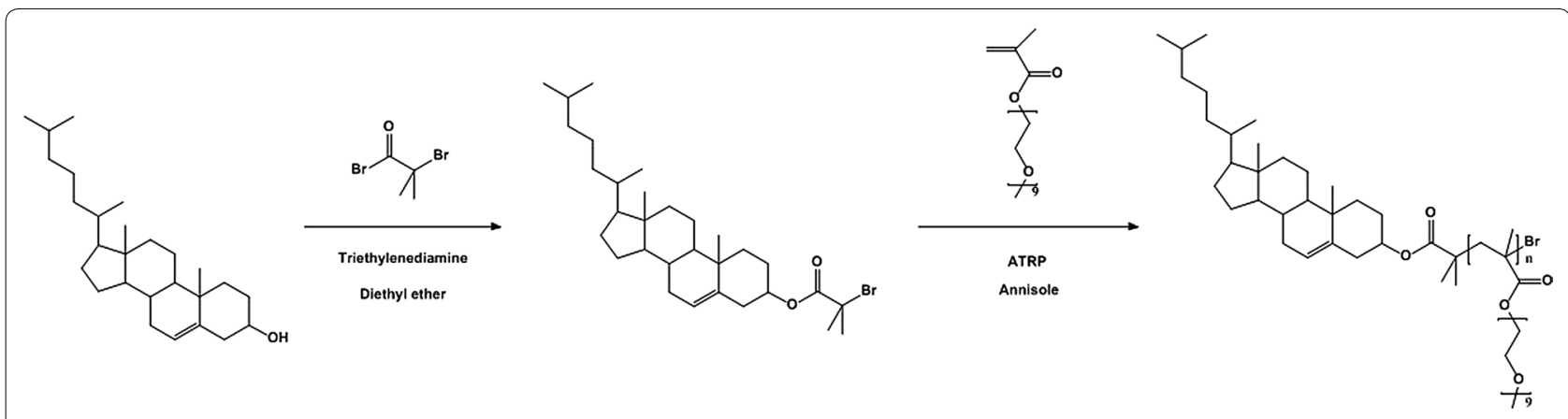

Fig. 2 Schematic steps of preparing cholesterol initiator (cholesterol-Br) and cholesterol-poly (OEGMA) amphiphilic polymer (CO) 


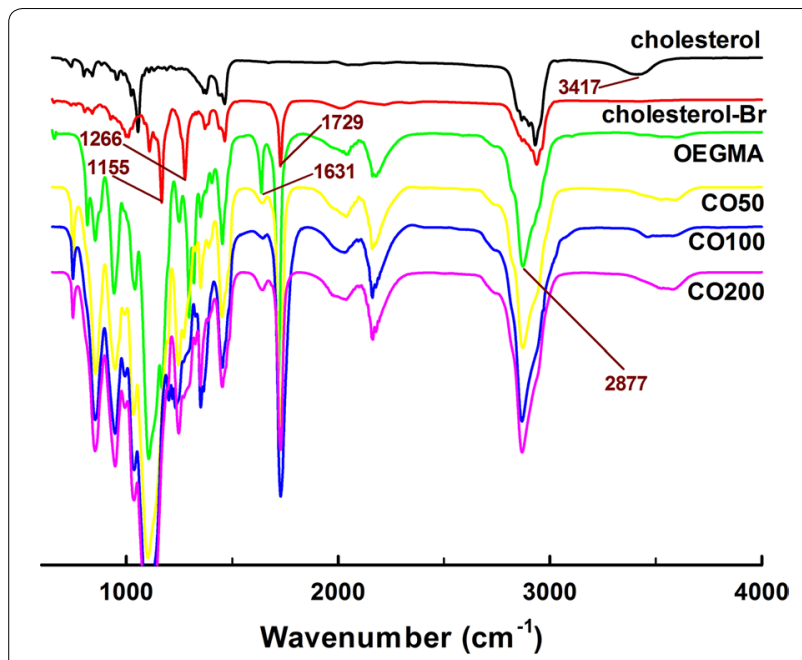

Fig. 3 FT-IR of samples: cholesterol, cholesterol-Br, OEGMA, CO50, CO100 and CO200

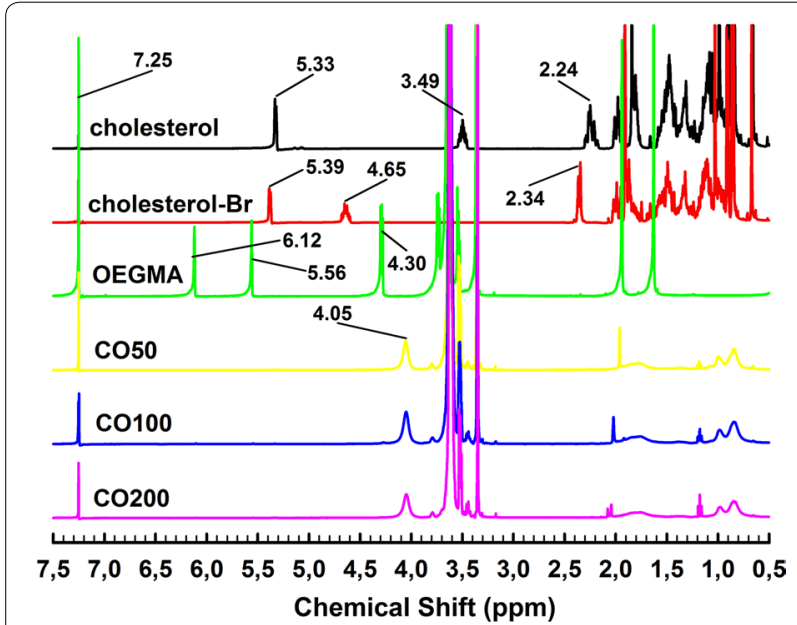

Fig. 4. ${ }^{1} \mathrm{H}$ NMR of samples: cholesterol, cholesterol-Br, OEGMA, CO50, $\mathrm{CO} 100$ and $\mathrm{CO} 200$ with solvent of $\mathrm{CDCl} 3$

And the chemical shift at $3.49 \mathrm{ppm}$ was corresponding to the $\mathrm{OH}$ groups of cholesterol not observed after modification for cholesterol-Br. The specific peak observed at $4.65 \mathrm{ppm}$ was the proton of isobutyryl groups for cholesterol-Br. In addition, the chemical shifts were respectively shown at 5.56 and $6.12 \mathrm{ppm}$ (protons of $\mathrm{C}=\mathrm{C}$ ), and $4.30 \mathrm{ppm}$ (protons of $-\mathrm{CH}_{2}-$ ) for OEGMA monomer. The final cholesterol end-capped polymer structure was confirmed using ${ }^{1} \mathrm{H}$ NMR, characterized by protons of $-\mathrm{CH}_{2}-$ at $4.05 \mathrm{ppm}$ for OEGMA and protons ranging from 0.5 to $2 \mathrm{ppm}$ for cholesterol. The disappearance of protons at 5.56 and $6.12 \mathrm{ppm}$ provided the information of total polymerization of OEGMA monomers.
Thermal properties of polymers and polymer-QC micelles The thermal properties of initiator, amphiphilic polymers, and polymer-QC complexes were investigated by TGA and DSC. Additional file 1: Figure S2 illustrated the weight loss ratio of cholesterol, cholesterol-Br, OEGMA monomer and $\mathrm{CO}$ polymers from $26^{\circ} \mathrm{C}$ to $600{ }^{\circ} \mathrm{C}$ under nitrogen gas atmosphere. The decomposition temperature of cholesterol- $\mathrm{Br}$ was $252.3{ }^{\circ} \mathrm{C}$, a slight increase from unmodified cholesterol $\left(250.8{ }^{\circ} \mathrm{C}\right)$. The OEGMA monomer had a broad decomposition temperature range from $150{ }^{\circ} \mathrm{C}$ to $400{ }^{\circ} \mathrm{C}$ while the corresponding decomposition temperature of synthesized $\mathrm{CO}$ polymers were respectively $283.1{ }^{\circ} \mathrm{C}$ for $\mathrm{CO} 50,291.3^{\circ} \mathrm{C}$ for $\mathrm{CO} 100$ and $303.3^{\circ} \mathrm{C}$ for $\mathrm{CO} 200$. The results showed that the decomposition temperature increased with the increase of polymer molecular weight. From the DSC results (Additional file 1: Figure S3), the apparent melting curve was observed at $39.2{ }^{\circ} \mathrm{C}$ for cholesterol while it shifted to $121.9{ }^{\circ} \mathrm{C}$ after modification to form cholesterol-Br. The increase of repeated units in $\mathrm{CO}$ polymers contributed to the close thermal ability between OEGMA monomer and CO polymers. Additional file 1: Figure S4 illustrated the TGA results of CO100-QC micelles. The melting curve was clearly observed at $68.9^{\circ} \mathrm{C}$ for drug QC and its weight loss ratio was around $63 \%$ during the temperature range from 26 to $600{ }^{\circ} \mathrm{C}$. Mostly, the weight loss ratios were $100 \%, 97 \%, 95 \%$ and $91.6 \%$ for CO100-QC respectively with the CO: QC weight ratio of 20:1, 10:1, 5: 1 and 2: 1 as well as the weight loss ratio of pure $\mathrm{CO} 100$ was nearly $100 \%$. Increasing the drug loading ratio induced higher decomposition temperature and lower weight loss ratio due to the increased amount of QC in the CO-QC complexes. Furthermore, it was also apparently presented that the melting peaks became more obvious and closer to pure QC with the increase of QC amount from CQ: $\mathrm{QC}=20: 1$ to 2: 1 (Additional file 1: Figure S5).

\section{CMC of polymer micelles}

$\mathrm{CMC}$ is one of the significant parameters for the preparation of polymer micelles as DDSs in biomedicines. Above $\mathrm{CMC}$, the amphiphilic polymers were expected to form polymer micelles in water by self-assembly. Furthermore, the fluorescent intensity of Pyrene is a molecular sensitive to the polarity of hydrophobic microenvironment and would be utilized as the fluorescent probe. At last the $C M C$ was obtained by linear regression of the plotted functions $A_{388 \mathrm{~nm}} / \mathrm{A}_{401 \mathrm{~nm}}$ from fluorescent microscopy. The original intensity versus concentration of CO100-pyrene was listed in Additional file 1: Figure S1. The fluorescent intensity increased with the increase of $\mathrm{CO}$ concentration. The ratios between selected intensities at $388 \mathrm{~nm}$ and $401 \mathrm{~nm}$ were plotted as the function to 
determine the CMC of polymer micelles (Fig. 5). Therefore, the $\mathrm{CMC}$ of $\mathrm{CO} 50, \mathrm{CO} 100$ and $\mathrm{CO} 200$ were respectively $2.53 \times 10^{-4}, 3.28 \times 10^{-4}$ and $4.33 \times 10^{-4} \mathrm{mg} / \mathrm{ml}$. The longer hydrophilic repeated units required higher concentration of amphiphilic polymer to form polymer micelles and further induced the higher $\mathrm{CMC}$ of polymers.

\section{Size and zeta potential of polymer and polymer-QC micelles}

The concentration of polymer micelles was $0.01 \mathrm{mg} / \mathrm{ml}$ in the final solution of PBS buffer $(\mathrm{pH}=7.4)$. The size and zeta potential of polymer micelles and polymer-QC micelles were initially analyzed by Zeta sizer at room temperature. Additional file 1: Figure S6 presented the size and zeta potential of different polymers-QC micelles with the weight ratio of 5: 1 prepared by dissolving them in THF after solvent evaporation in PBS buffer. The size and zeta potentials were $243.0 \pm 15.1 \mathrm{~nm}$ and $-9.5 \pm 0.3$ for CO50 micelles while they became 184.9 $\pm 9.2 \mathrm{~nm}$ and $-13.0 \pm 2.1$ for CO100, and 155.9 $\pm 7.1 \mathrm{~nm}$ and - $12.2 \pm 0.5$ for CO200. It seemed that the higher molecular weight $(\mathrm{Mw})$ of polymers always provided the smaller size and lower zeta potential of polymer micelles. After QC loading in CO50, the corresponding size and zeta potential changed to $377.3 \pm 14.7 \mathrm{~nm}$ and $-17.1 \pm 1.9$. It was the same situation that the size of polymer micelles increased, and their corresponding zeta potential decreased after QC loading in polymer micelles for CO100 and CO200. Higher molecular weight means the longer hydrophilic chain of CO polymers, which could contribute not only the smaller size but also stronger stability of polymer micelles.

The weight ratio of CO100: QC was also expected to affect the size and zeta potential of polymer micelles. From Additional file 1: Figure S7, the size was

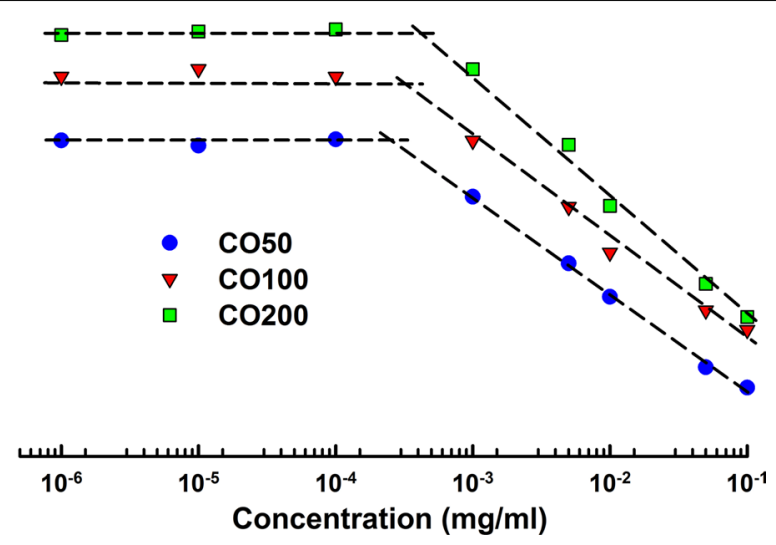

Fig. 5 Plot of I388/1401 (from pyrene emission spectra by fluorescent microscopy) versus the concentration of CO50, CO100 and CO200 ranging from $1 \times 10^{-6}$ to $0.1 \mathrm{mg} / \mathrm{ml}$
$192.0 \pm 24.5 \mathrm{~nm}, 263.8 \pm 27.6 \mathrm{~nm}, 385.7 \pm 55.6 \mathrm{~nm}$ and $534.4 \pm 15.5 \mathrm{~nm}$ for polymer-QC complexes with CO100: QC weight ratio from 20:1, 10: 1, 5: 1 and 2: 1 . Their zeta potentials also gently decreased from $-18.3 \pm 0.8$ for 20: 1 to $-24.7 \pm 1.4$ for 2 : 1 . The solubility of polymers and QC in different solvents also had the effects on size and zeta potential of micelles. Additional file 1: Figure S8 illustrated the size and zeta potential of polymer micelles prepared by dissolving polymer and/or QC in different solvents after the evaporation of solvents in PBS buffer $(\mathrm{pH}=7.4)$. The size and corresponding zeta potential respectively was $134.4 \pm 15.5 \mathrm{~nm}$ and $-21.2 \pm 2.1$ for methanol, $184.9 \pm 9.2 \mathrm{~nm}$ and $-13.0 \pm 2.1$ for THF, $225.8 \pm 35.0 \mathrm{~nm}$ and $-11.90 \pm 1.6$ for acetone, and $235.1 \pm 31.4 \mathrm{~nm}$ and $-3.6 \pm 0.8$ for DCM. The good solubility was helpful to provide homogeneous dispersion of polymers so that the size of polymer micelles became smaller and their stabilities also increased in the presence of increased absolute value of zeta potential. Correspondingly the poor solvents induced the irregular aggregation of polymers and destabilized the polymer micelles.

In addition, the size of $\mathrm{CO}$ and $\mathrm{CO}-\mathrm{QC}$ micelles was investigated by SEM and AFM. Figure 6 illustrated the AFM and SEM results of CO100 and CO100-QC (weight ratio of 5: 1) micelles in DI water. The size of pure CO100 micelles was below $200 \mathrm{~nm}$ in diameter (Fig. 6a, c) while the size obviously increased (200-300 nm) after QC loading with the weight ratio of 5: 1 (Fig. 6b, d), which was the same conditions for CO50 before and after QC loading with the same weight ratio (Additional file 1: Figures S9 and S10). The size of micelles became bigger (around $300 \mathrm{~nm}$ ) by increasing $\mathrm{QC}$ weight to $\mathrm{CO}: \mathrm{QC}=2: 1$ (Additional file 1: Figure S11).

\section{Drug loading ratio of polymer micelles}

The drug-loading ratio was obtained by calculating UV absorbance based on the QC standard curve. From Fig. 7 , the drug loading ratio was $15.56 \pm 0.75 \%$ for $\mathrm{CO} 50$, which slightly decreased to $14.13 \pm 0.39 \%$ for $\mathrm{CO} 100$ and $14.10 \pm 0.16 \%$ for $\mathrm{CO} 200$ with CO: QC weight ratio of 5 : 1 and prepared by dissolving $\mathrm{CO}$ and QC in THF after solvents evaporation in PBS buffer $(\mathrm{pH}=7.4)$. If increasing the CO: QC weight ratio from 20: 1, 10: 1 to 2: 1 , their QC loading ratio respectively became $2.60 \pm 0.12 \%$, $4.91 \pm 1.06 \%$ and $29.21 \pm 0.73 \%$. However, QC loading ratio was $11.64 \pm 0.39 \%$ and $13.81 \pm 0.80 \%$ by separately changing the solvent to acetone and methanol (weight ratio of 5: 1). Good solvents for $\mathrm{CO}$ and $\mathrm{QC}$ were also beneficial to increase the drug loading.

\section{Cell cytotoxicity of polymer-QC micelles}

The aim of developing DDSs is to reduce the cytotoxicity of drugs and avoid the deletion of medicinal effect. 

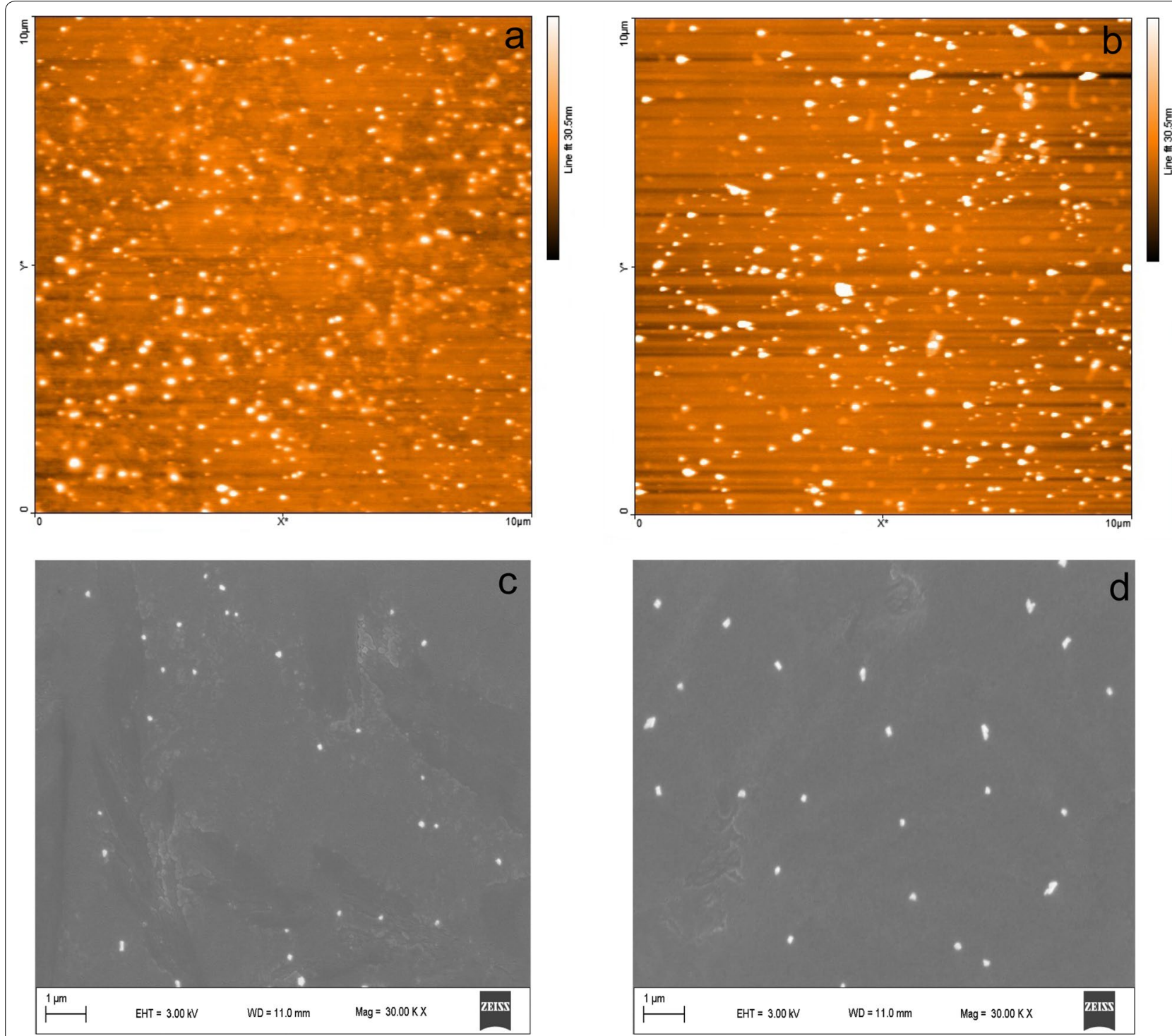

Fig. 6 AFM and SEM images of CO100 (a, c) and CO100-QC (weight ratio of 5: 1, b, d) micelles prepared by dissolving the CO100 and/or QC in THF after solvent evaporation in DI water to reach $0.01 \mathrm{mg} / \mathrm{ml} \mathrm{CO} 100$ in the final solution

The cell cytotoxicity of CO-QC micelles was investigated by mixing them with cultured cells for $24 \mathrm{~h}$. For free QC medium, $91.4 \%$ of cells were dead after $24 \mathrm{~h}$ of incubation. The cell viability of CO100-QC micelles was $50.1 \%$ while the pure CO100 micelle still killed $29.9 \%$ of cells. Therefore, QC loaded polymer micelles could effectively decrease the toxicity of pure QC under the same condition. (Fig. 8).

\section{In vitro release of $Q C$}

The release of QC from defined medium was monitored by UV detector of HPLC and the release ratio was calculated based on obtained UV absorbance of
$0.02 \mathrm{mg} / \mathrm{ml} \mathrm{QC}$ in the corresponding defined medium by HPLC. The total release time of free $\mathrm{QC}$ was within $24 \mathrm{~h}$ for $\mathrm{pH}=4.0$ PBS buffer (QC-pH4.0 in Fig. 9) while it changed to below $4 \mathrm{~h}$ for $\mathrm{pH}=7.4 \mathrm{PBS}$ buffer (QC$\mathrm{pH} 7.4)$. After forming CO100-QC polymer micelles (CO100: $\mathrm{QC}=5: 1,0.1 \mathrm{mg} / \mathrm{ml} \mathrm{CO100} \mathrm{in} \mathrm{final} \mathrm{solution),}$ the release time simultaneously grew to above $48 \mathrm{~h}$ for both $\mathrm{pH}=4.0(\mathrm{CO}-\mathrm{pH} 4.0)$ and $\mathrm{pH}=7.4(\mathrm{CO}-\mathrm{pH} 7.4)$ PBS buffer. However, the addition of $\beta$-cyclodextrin $(0.1 \mathrm{mg} / \mathrm{ml}$ in final solution) significantly induced the fast release of QC. Therefore, the release time of CO-QC samples became below $8 \mathrm{~h}$ for PBS buffer with $\beta$-cyclodextrin (QC-CD-pH4.0 and QC-CD-pH7.4). 


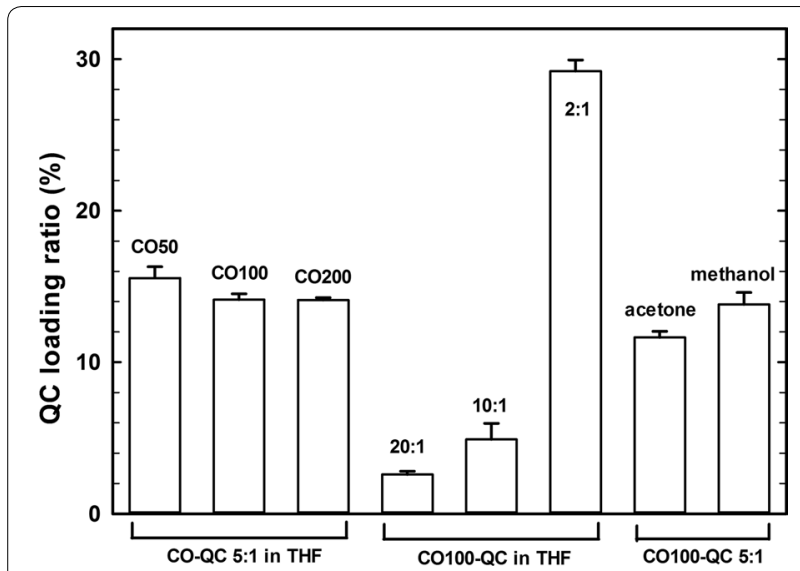

Fig.7 QC loading ratio of CO micelles prepared by different types of $\mathrm{CO}$ polymers (CO50, CO100 and CO200) respectively dissolved in different solvents (acetone, methanol and THF) with different CO: QC weight ratio of 20: 1, 10: 1, 5:1 and 2:1 after solvents evaporation to reach the $\mathrm{CO}$ concentration of $0.1 \mathrm{mg} / \mathrm{ml}$ in the final solution

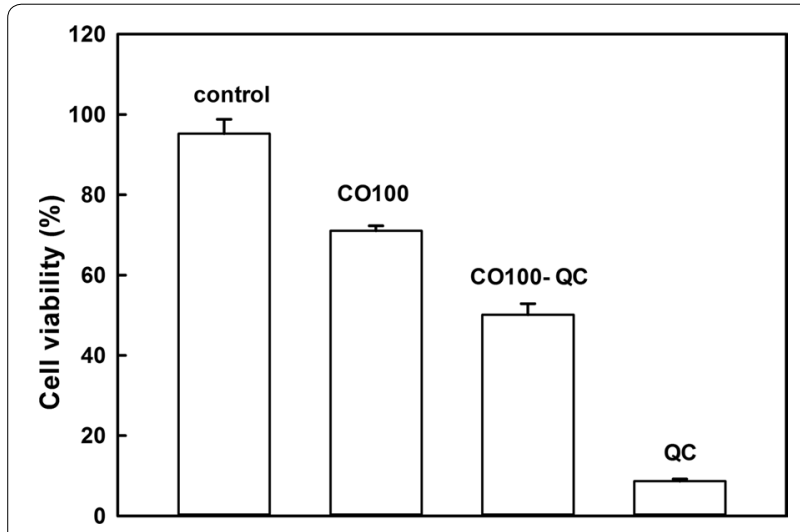

Fig. 8 C2C12 cell viability cultured with $0.1 \mathrm{mg} / \mathrm{ml}$ CO100, $0.1 \mathrm{mg} /$ $\mathrm{ml} \mathrm{CO100-QC} \mathrm{micelles} \mathrm{(CO100:} \mathrm{QC}=5: 1$ ), and $0.02 \mathrm{mg} / \mathrm{ml} \mathrm{QC}$ in the final solution after incubation for $24 \mathrm{~h}$

QC was more soluble in $\mathrm{pH}=7.4$ PBS buffer than $\mathrm{pH}=4.0$ PBS buffer so that $\mathrm{QC}$ was easily released in higher $\mathrm{pH}$ PBS buffer. The formation of CO-QC micelles resulted in the slow release of QC in PBS buffer. However, the quick QC release was achieved by host-guest interaction between cholesterol groups of $\mathrm{CO}$ and $\beta$-cyclodextrin which could destabilize the hydrophobic domain of cholesterol and QC.

\section{Conclusions}

The cholesterol end-capped amphiphilic polymers were applied to form quercetin (QC) loaded micelles by self-assembly in aqueous solution after solvent evaporation to obtain controlled DDSs. TGA, DSC and UV spectroscopy were used to investigate the QC loading

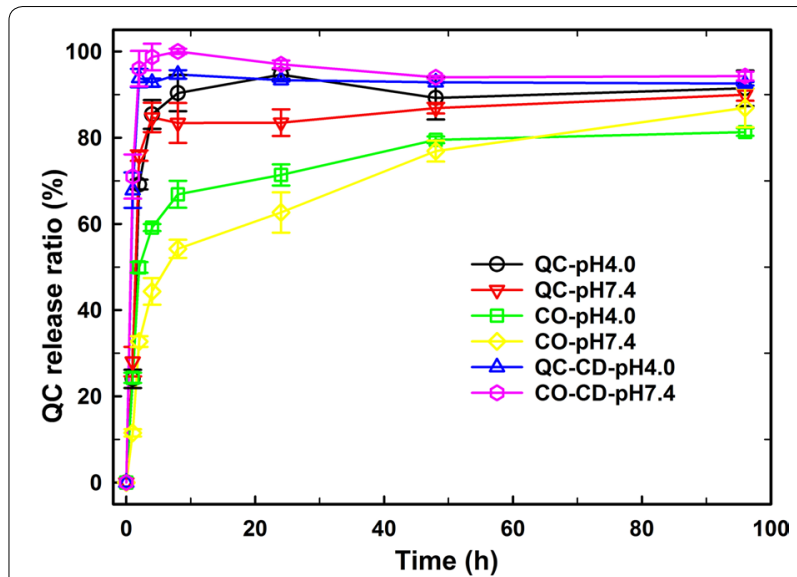

Fig. 9 In vitro QC release ratio of different samples under different defined medium. They are: free QC $(0.02 \mathrm{mg} / \mathrm{ml})$ in PBS buffer of $\mathrm{pH}=4$ (QC-pH4.0) and pH=7.4 (QC-pH7.4), CO100-QC $(0.1 \mathrm{mg} / \mathrm{ml}$ CO100, $\mathrm{CO}: \mathrm{QC}=5: 1)$ micelles in PBS buffer of $\mathrm{pH}=4.0(\mathrm{CO}-\mathrm{pH} 4.0)$ and $\mathrm{pH}=7.4(\mathrm{CO}-\mathrm{pH} 7.4)$, and $\mathrm{CO} 100-\mathrm{QC}(5: 1)$ micelles in $\mathrm{pH}=4.0$ and $\mathrm{pH}=7.4 \mathrm{PBS}$ buffer with $0.1 \mathrm{mg} / \mathrm{ml} \beta$-cyclodextrin (CO-QC $\mathrm{pH} 4.0$ and $\mathrm{CO}-\mathrm{QC} \mathrm{pH} 7.4)$

ratio determined by $\mathrm{CMC}$ of polymer micelles, weight ratio between amphiphilic polymer and QC as well as the solubility of polymers/QC in different solvents. It was found that the size of polymer-QC micelles was in hundreds nm scale by DLS, AFM and SEM, which could be easily uptake by cultured cells. It also demonstrated that in vitro release of polymer-QC micelles not only alleviated the cytotoxicity of $\mathrm{QC}$, but was controlled under different conditions, e.g. $\mathrm{pH}$ and presence of cyclodextrins in the released medium. The results observed in this study offered a strong foundation for the design of favorable polymer micelles as systems for controlled drug release.

\section{Supplementary information}

Supplementary information accompanies this paper at https://doi. org/10.1186/s12951-020-0575-y.

Additional file 1: Figure S1. Fluorescent intensity of CO100-pyrene micelles prepared by dissolving $\mathrm{CO} 100$ and pyrene in THF after solvent evaporation in PBS buffer $(0.01 \mathrm{mg} / \mathrm{ml} \mathrm{CO} 100$ in final solution, $\mathrm{pH}=7.4)$. Figure S2. TGA results of cholesterol, cholesterol-Br, OEGMA monomer and amphiphilic polymers $\mathrm{CO} 50, \mathrm{CO} 100$ and CO200. The heating speed is $5^{\circ} \mathrm{C} / \mathrm{min}$ from room T to $600^{\circ} \mathrm{C}$ under $\mathrm{N}_{2}$ atmosphere. Figure S3. DSC results of cholesterol, cholesterol-Br, OEGMA monomer and amphiphilic polymers $\mathrm{CO} 50, \mathrm{CO} 100$ and $\mathrm{CO} 200$. The heating flow is $10^{\circ} \mathrm{C} / \mathrm{min}$ from room T to $200^{\circ} \mathrm{C}$. Figure S4. TGA results of CO100, QC and CO100-QC complexes with different CO: QC weight ratio of 20: 1, 10: 1, 5: 1 and 2: 1 . The heating speed is $5^{\circ} \mathrm{C} / \mathrm{min}$ from room T to $600^{\circ} \mathrm{C}$ under $\mathrm{N}_{2}$ atmosphere. Figure S5. DSC results of CO100, QC and CO100-QC complexes with different CO: QC weight ratio of 20: 1, 10: 1,5:1 and 2: 1. The heating flow is $10^{\circ} \mathrm{C} / \mathrm{min}$ from room $\mathrm{T}$ to $200^{\circ} \mathrm{C}$. Figure S6. Size and zeta potential of different types of $\mathrm{CO}$ and $\mathrm{CO}-\mathrm{QC}$ micelles with the $\mathrm{CO}: \mathrm{QC}$ weight ratio of $5: 1$ in PBS buffer $(\mathrm{pH}=7.4)$. The concentration of $\mathrm{CO}$ polymers is 0.01 $\mathrm{mg} / \mathrm{ml}$ in the final solution. Figure S7. Size and zeta potential of $\mathrm{CO} 100$ 
and CO100-QC micelles with different CO: QC weight ratio of 20: 1, 10: 1, 5:1 and 2:1 in PBS buffer ( $\mathrm{pH}=7.4)$. The concentration of $\mathrm{CO}$ polymers is $0.01 \mathrm{mg} / \mathrm{ml}$ in the final solution. Figure $\mathbf{S} 8$. Size and zeta potential of CO100 and CO100-QC complexes with CO: QC weight ratio of 5: 1 prepared by dissolving the $\mathrm{CO} 100$ and/or QC in different solvents (acetone, DCM, methanol and THF) after solvents evaporation in PBS buffer $(\mathrm{pH}=$ 7.4). The concentration of $\mathrm{CO}$ polymers is $0.01 \mathrm{mg} / \mathrm{ml}$ in the final solution. Figure S9. SEM image of CO50 polymer micelles prepared by dissolving CO50 in THF after solvent evaporation in DI water to reach $0.01 \mathrm{mg} / \mathrm{ml}$ CO50 in the final solution. Figure S10. SEM image of CO50-QC micelles (CO: $\mathrm{QC}=5: 1$ ) prepared by dissolving $\mathrm{CO} 50$ and $\mathrm{QC}$ in THF after solvent evaporation in DI water to reach $0.01 \mathrm{mg} / \mathrm{ml} \mathrm{CO} 50$ in the final solution. Figure S11. SEM image of CO100-QC micelles (CO: $\mathrm{QC}=2: 1$ ) prepared by dissolving $\mathrm{CO} 100$ and QC in THF after solvent evaporation in DI water to reach $0.01 \mathrm{mg} / \mathrm{ml} \mathrm{CO} 100$ in the final solution.

\section{Abbreviations}

ATRP: atom transfer radical polymerization; CMC: critical micelle concentration; QC: quercetin; DDS: drug delivery system; Mw: weight-average molecular weight; PDI: polymer disperse index.

\section{Acknowledgements}

Not applicable.

\section{Authors' contributions}

$M G, L Z$ and $T B$ designed the experiments and give the intellectual input. $M G$ $Y Y, A B$, and $L H$ performed the experiments and analyzed the data. $L Z$ and $T B$ supervised the experiments and edited the final version of the manuscript. All authors read and approved the final manuscript.

\section{Funding}

This study was financially supported by National Key R\&D Program of China (2018YFC1105900), the Guangxi Science and Technology Base and Talent Special Project (Grant No. GuikeAD17129012), and the local Science and Technology Development Project leading by the central government (the three-D printing and digital medical platform, Grant No. GuikeZY18164004).

\section{Availability of data and materials}

All data generated or analyzed during this study are included in this published article.

\section{Ethics approval and consent to participate}

Not applicable.

\section{Consent for publication}

All authors have provided consent for the manuscript to be published.

\section{Competing interests}

The authors declare that they have no competing interests.

\section{Author details \\ ${ }^{1}$ Guangxi Engineering Center in Biomedical Materials for Tissue and Organ Regeneration, The First Affiliated Hospital of Guangxi Medical Univer- sity, Nanning 530021, China. ${ }^{2}$ Guangxi Collaborative Innovation Center for Biomedicine, The First Affiliated Hospital of Guangxi Medical University, Nanning 530021, China. ${ }^{3}$ Department of Chemistry-Ångström Laboratory, Uppsala University, Box 538, 75121 Uppsala, Sweden. ${ }^{4}$ Pharmaceutical Col- lege, Guangxi Medical University, Nanning 530021, China.}

Received: 23 October 2019 Accepted: 7 January 2020

Published online: 15 January 2020

\section{References}

1. Lindsay MA. Target discovery. Nat Rev Drug Discov. 2003;2(10):831-8.
2. Hoelder S, Clarke PA, Workman P. Discovery of small molecule cancer drugs: successes, challenges and opportunities. Mol Oncol. 2012;6(2):155-76.

3. Park K. Controlled drug delivery systems: past forward and future back. J Control Release. 2014;190:3-8.

4. Tibbitt MW, Dahlman JE, Langer R. Emerging frontiers in drug delivery. J Am Chem Soc. 2016;138(3):704-17.

5. de la Rica R, Aili D, Stevens MM. Enzyme-responsive nanoparticles for drug release and diagnostics. Adv Drug Deliv Rev. 2012;64(11):967-78.

6. Torchilin VP. Multifunctional, stimuli-sensitive nanoparticulate systems for drug delivery. Nat Rev Drug Discov. 2014;13(11):813-27.

7. Liu T-Y, Liu K-H, Liu D-M, Chen S-Y, Chen IW. Temperature-sensitive nanocapsules for controlled drug release caused by magnetically triggered structural disruption. Adv Func Mater. 2009;19(4):616-23.

8. Mora-Huertas CE, Fessi H, Elaissari A. Polymer-based nanocapsules for drug delivery. Int J Pharm. 2010;385(1-2):113-42.

9. Kedar U, Phutane P, Shidhaye S, Kadam V. Advances in polymeric micelles for drug delivery and tumor targeting. Nanomed Nanotechnol Biol Med. 2010;6(6):714-29.

10. Ahmad Z, Shah A, Siddiq M, Kraatz H-B. Polymeric micelles as drug delivery vehicles. RSC Adv. 2014;4(33):17028-38.

11. Allen TM, Cullis PR. Liposomal drug delivery systems: From concept to clinical applications. Adv Drug Deliv Rev. 2013;65(1):36-48.

12. Pattni BS, Chupin WV, Torchilin VP. New developments in liposomal drug delivery. Chem Rev. 2015;115(19):10938-66.

13. He C, Hu Y, Yin L, Tang C, Yin C. Effects of particle size and surface charge on cellular uptake and biodistribution of polymeric nanoparticles. Biomaterials. 2010;31(13):3657-66.

14. Salatin S, Maleki Dizaj S, Yari Khosroushahi A. Effect of the surface modification, size, and shape on cellular uptake of nanoparticles. Cell Biol Int. 2015:39(8):881-90.

15. Xiong X-B, Binkhathlan Z, Molavi O, Lavasanifar A. Amphiphilic block co-polymers: preparation and application in nanodrug and gene delivery. Acta Biomater. 2012;8(6):2017-33.

16. Sundaram HS, Cho Y, Dimitriou MD, Finlay JA, Cone G, Williams S, Handlin D, Gatto J, Callow ME, Callow JA, Kramer EJ, Ober CK. Fluorinated amphiphilic polymers and their blends for fouling-release applications: the benefits of a triblock copolymer surface. ACS Appl Mater Interfaces. 2011;3(9):3366-74.

17. Decato S, Bemis T, Madsen E, Mecozzi S. Synthesis and characterization of perfluoro-tert-butyl semifluorinated amphiphilic polymers and their potential application in hydrophobic drug delivery. Polym Chem. 2014;5(22):6461-71.

18. Venkataraman S, Lee AL, Maune HT, Hedrick JL, Prabhu VM, Yang YY. Formation of disk- and stacked-disk-like self-assembled morphologies from cholesterol-functionalized amphiphilic polycarbonate diblock copolymers. Macromolecules. 2013;46(12):4839-46.

19. Wang Z, Luo T, Sheng R, Li H, Sun J, Cao A. Amphiphilic diblock terpolymer PMAgala-b-P(MAA-co-MAChol)s with attached galactose and cholesterol grafts and their intracellular $\mathrm{pH}$-responsive doxorubicin delivery. Biomacromol. 2016;17(1):98-110.

20. Feng C, Lu G, Li Y, Huang X. Self-assembly of amphiphilic homopolymers bearing ferrocene and carboxyl functionalities: effect of polymer concentration, $\beta$-cyclodextrin, and length of alkyl linker. Langmuir. 2013;29(34):10922-31.

21. Liu L, Rui L, Gao Y, Zhang W. Self-assembly and disassembly of a redoxresponsive ferrocene-containing amphiphilic block copolymer for controlled release. Polym Chem. 2015;6(10):1817-29.

22. Vybornyi M, Rudnev AV, Langenegger SM, Wandlowski T, Calzaferri G, Häner R. Formation of two-dimensional supramolecular polymers by amphiphilic pyrene oligomers. Angew Chem Int Ed. 2013;52(44):11488-93.

23. Vybornyi M, Rudnev A, Häner R. Assembly of extra-large nanosheets by supramolecular polymerization of amphiphilic pyrene oligomers in aqueous solution. Chem Mater. 2015;27(4):1426-31.

24. Yang $X$, Zhu B, Dong T, Pan $P$, Shuai $X$, Inoue Y. Interactions between an anticancer drug and polymeric micelles based on biodegradable polyesters. Macromol Biosci. 2008;8(12):1116-25.

25. Stefani S, Kurniasih IN, Sharma SK, Bottcher C, Servin P, Haag R. Triglycerolbased hyperbranched polyesters with an amphiphilic branched 
shell as novel biodegradable drug delivery systems. Polym Chem. 2016;7(4):887-98.

26. Gu L, Faig A, Abdelhamid D, Uhrich K. Sugar-based amphiphilic polymers for biomedical applications: from nanocarriers to therapeutics. Acc Chem Res. 2014;47(10):2867-77.

27. Wang Q-M, Gao Z, Liu S, Fan B, Kang L, Huang W, Jin M. Hybrid polymeric micelles based on bioactive polypeptides as pH-responsive delivery systems against melanoma. Biomaterials. 2014;35(25):7008-211.

28. Ramasamy T, Choi JY, Cho HJ, Umadevi SK, Shin BS, Choi H-G, Yong CS, Kim JO. Polypeptide-based micelles for delivery of irinotecan: physicochemical and in vivo characterization. Pharm Res. 2015:32(6):1947-56.

29. Danprasert K, Kumar R, Cheng MH, Gupta P, Shakil NA, Prasad AK, Parmar VS, Kumar J, Samuelson LA, Watterson AC. Synthesis of novel poly(ethylene glycol) based amphiphilic polymers. Eur Polym J. 2003;39(10):1983-90.

30. Sezgin Z, Yüksel N, Baykara T. Preparation and characterization of polymeric micelles for solubilization of poorly soluble anticancer drugs. Eur J Pharm Biopharm. 2006;64(3):261-8.

31. Cho I, Jeong SW. Cholesterol-containing non-ionic amphiphilic polymers: synthesis and solubilization of cholesterol. Macromol Chem Phys. 1995;196(3):869-75.

32. Gao Y, Ahiabu A, Serpe MJ. Controlled drug release from the aggregationdisaggregation behavior of $\mathrm{pH}$-responsive microgels. ACS Appl Mater Interfaces. 2014:6(16):13749-56.

33. Lee SC, Lee HJ. pH-Controlled, polymer-mediated assembly of polymer micelle nanoparticles. Langmuir. 2007;23(2):488-95.

34. Wang X, Cai X, Hu J, Shao N, Wang F, Zhang Q, Xiao J, Cheng Y. Glutathione-triggered "off-on" release of anticancer drugs from dendrimerencapsulated gold nanoparticles. J Am Chem Soc. 2013;135(26):9805-10.

35. Xu Z, Liu S, Kang Y, Wang M. Glutathione-responsive polymeric micelles formed by a biodegradable amphiphilic triblock copolymer for anticancer drug delivery and controlled release. ACS Biomater Sci Eng. 2015;1 (7):585-92.

36. Hu Q, Katti PS, Gu Z. Enzyme-responsive nanomaterials for controlled drug delivery. Nanoscale. 2014;6(21):12273-86.

37. Lu J, Choi E, Tamanoi F, Zink JI. Light-activated nanoimpeller-controlled drug release in cancer cells. Small. 2008;4(4):421-6.
38. Nappini S, Bonini M, Bombelli FB, Pineider F, Sangregorio C, Baglioni P, Norden B. Controlled drug release under a low frequency magnetic field: effect of the citrate coating on magnetoliposomes stability. Soft Matter. 2011;7(3):1025-37.

39. Oliveira H, Pérez-Andrés E, Thevenot J, Sandre O, Berra E, Lecommandoux S. Magnetic field triggered drug release from polymersomes for cancer therapeutics. J Control Release. 2013;169(3):165-70.

40. Peng K, Cui C, Tomatsu I, Porta F, Meijer AH, Spaink HP, Kros A. Cyclodextrin/dextran based drug carriers for a controlled release of hydrophobic drugs in zebrafish embryos. Soft Matter. 2010;6(16):3778-833.

41. Ma Z, Taylor J-S. Nucleic acid-triggered catalytic drug release. Proc Natl Acad Sci. 2000;97(21):11159-63.

42. Matyjaszewski K. Atom transfer radical polymerization (ATRP): current status and future perspectives. Macromolecules. 2012;45(10):4015-39.

43. Bergfelt A, Lacey MJ, Hedman J, Sångeland C, Brandell D, Bowden T. $\varepsilon$-Caprolactone-based solid polymer electrolytes for lithium-ion batteries: synthesis, electrochemical characterization and mechanical stabilization by block copolymerization. RSC Adv. 2018;8(30):16716-25.

44. Bergfelt A, Rubatat L, Brandell D, Bowden T. Poly(benzyl methacrylate)poly[(oligo ethylene glycol) methyl ether methacrylate] triblockcopolymers as solid electrolyte for lithium batteries. Solid State lonics. 2018:321:55-61.

45. Wilhelm M, Zhao CL, Wang Y, Xu R, Winnik MA, Mura JL, Riess G, Croucher MD. Poly(styrene-ethylene oxide) block copolymer micelle formation in water: a fluorescence probe study. Macromolecules. 1991;24(5):1033-40.

46. Zhang J, Wang L-Q, Wang $H$, Tu K. Micellization phenomena of amphiphilic block copolymers based on methoxy poly(ethylene glycol) and either crystalline or amorphous poly(caprolactone-b-lactide). Biomacromol. 2006;7(9):2492-500

\section{Publisher's Note}

Springer Nature remains neutral with regard to jurisdictional claims in published maps and institutional affiliations.

Ready to submit your research? Choose BMC and benefit from:

- fast, convenient online submission

- thorough peer review by experienced researchers in your field

- rapid publication on acceptance

- support for research data, including large and complex data types

- gold Open Access which fosters wider collaboration and increased citations

- maximum visibility for your research: over 100M website views per year

At BMC, research is always in progress.

Learn more biomedcentral.com/submissions 